\title{
Human Resource Management: Ways to create positive Working Environment
}

\author{
Dr. Anil P Sarode, M.J. College, Jalgaon \\ Mrs. Manisha Shirsath, Ashoka Center for Business \& computer Studies,Nasik
}

\begin{abstract}
What is it that makes one workplace environment conducive to innovation, enthusiasm, and commitment while another is not? Why is it that you can walk into a workplace and feel the energy sparking? What is it about a similar environment that leads to boredom and lack of attention? This paper addresses these important questions and focuses on the key elements like build trust, Communicate positively and openly, Create Team Spirit , Be Approachable, Be social and many more that create a positive environment in the workplace and the role leadership plays in fostering that environment. The purpose of this paper is to explore the key elements that comprise a productive and highly energized workplace environment in which people flourish. Do the elements of a high performing environment differ from person to person? Are there universal elements that, when in place, allow people to be magnificent and perform at superior levels, constantly stretching, growing, and being the best they can be? If so, what are these elements and how do leaders create or influence such environments?
\end{abstract}

Key words: Workplace Environment, Team Spirit, innovation, enthusiasm, commitment

\section{Introduction}

We have all worked at places that we were less than excited to get up in the mornings and go to; this is an awful feeling. It is much more pleasurable, and less stressful to go to a work environment that is filled with positivity and enjoyment. A positive work environment is not only important for our physical, mental and emotional health, but is also important for the results that we produce for the company. A positive work environment needs to be given much attention so we have the stamina to deal with our work for years. A positive office environment can always give us a chance to provide more ideas, deliver more and earn more. The better we feel at work, the more likely we will take pride in our job activities and be loyal towards our place of employment.

There are several things a leader/manager can do to make your work environment a positive one and to facilitate a feeling of cooperation, teamwork and joy among your staff. Some of these are:

\section{Build Trust}

Trust is the basic tenant for all relationships, so building an environment of trust is one of the most important things you can do to create a positive work environment. It's a philosophy that must be demonstrated in everything you and your staff does. Trust is about doing what you say you are going to do and being who you say you are. It's about showing your staff in everything you do that you are reliable, responsible and accountable, and that they can rely on you for consistency. Also letting them know you expect the same from them. When your words and behavior are congruent you foster trust. It will take some time for your staff members to learn that you are a person of your word. If they see that you are consistent you will build trust, but if they see your words don't match your behaviors their trust in you will be destroyed. The unfortunate thing about trust is that it takes a long time to build, but it's very fragile and will break easily. Once broken, it takes an even longer time to regain, and it may never be fully rebuilt. Therefore, it is of primary importance that you are aware of all your words and behaviors and insure that they are worthy of your employees' trust.

Even when dealing with uncomfortable situations, if you are honest and up front it will make things easier for everyone. What you say and what you do represent who you are. Even if they don't like what you are saying, if you say it honestly, compassionately and tactfully they will respect and trust you. Your employees' level of trust will also be determined by how well you keep confidences and don't disclose discussions that have been held in private. They have to know they can talk with you about sensitive subjects and that the information they share with you will be kept in strict confidence. Confidentiality is critical in all aspects of your job. This also applies to never discussing one employee with another, except in positive terms. Any problems you are having with a team member must be kept between you and that employee, and your supervisor, if applicable. A good manager never talks negatively about his/her team. 


\section{Communicate positively and openly.}

In order to create a positive work environment each employee needs to feel valued. This is best accomplished through your listening to each person and honoring each one for what s/he has to say. By doing this you will show that you value and respect every individual. One important aspect of communicating openly is to meet with your staff and discuss your organization's philosophy, values, mission and goals. Ask for their ideas and thoughts on how they individually and as a team can help your unit to exemplify these. Then lead a discussion on the ways they all see these being fulfilled within your work group. After your staff has shared their ideas, take time to share your own vision of how you see everyone working together. Share how you see everyone working together as a circle in which everyone is equal and on the same level, rather than a pyramid where supervisors and administrators are at the top, and the staff is at the bottom. Everyone is equal because every job is equally important in fulfilling the mission of the organization. Also share your work ethic, commitment to the job and facility, and your values. Talking about and modeling your own work ethic will set an example of what your expectations are for your staff and their behavior. This includes:

" Being accountable to the job. " Showing up on time and with a positive attitude. " Being willingly taking on tasks and assignments. " Being proud of your facility and that you are a part of it. " Treating everyone with respect and in a friendly manner. " Focusing on work and leaving personal issues outside the workplace. " Seeing your work as an opportunity for continuous personal growth and lifelong learning.

Sometimes it helps with a discussion like this to use a board or flip chart and colored pens so you can write thoughts, goals and ideas as your team comes up with them. If they are having a hard time getting started, you can write three of your own goals and then ask the group to add to the list. This exercise will help all of your team members focus on where they would like to see the unit be in the next six months. These goals can then be reviewed at staff meetings to see how they are being met. It's through these means of open communication that each member of the work group understands how they fit into the unit and how they impact where it is going.

\section{Expect The Best From Your Staff}

There is a concept called 'The Self-Fulfilling Prophecy' which states that people generally will perform in the way others expect them to perform. So, if you have high expectations for your staff, treat them as if they are capable, competent people and expect them to function as such, they will rise to the occasion and be the excellent employees you see them to be. However, if you micromanage them, expect them to be mediocre and treat them as if they can't function well on their own, that is the behavior they will give you. A good supervisor always has high expectations for his/her staff and treats them accordingly.

\section{Create Team Spirit}

One of our basic human needs is to feel we belong to something bigger than ourselves, and for many people that need is met by being part of a supportive work group. As a supervisor, part of your job is to create a feeling of unity among your staff. This unity will help your team members feel valued and that they belong. As a result they will want to be at work, tardiness and absenteeism will be minimal, your team will function smoothly and your unit will be better able to carry out the missions and goals of your organization.

To foster this team feeling you must convey to the entire staff that every person plays an important role. Encourage an attitude of cooperation rather than competition. When you create team spirit and identity, staff members will see themselves as a group of people all working for a common goal, rather than a bunch of individuals competing with each other.

By letting each member know they are a valued part of the team you will teach your staff members to respect each other for their unique contributions. There are many group exercises designed to foster this kind of unity. One easy exercise is to begin staff meetings by going around the table and having each person say one nice thing about the person on their right or left. Especially things they've noticed about how they care for the residents. Acknowledging behaviors such as the way Madison approaches residents with a gentle touch and always says their name, or how Joe inquires if a resident is warm enough and offers to bring a blanket. The way Ben shows he values the residents by taking the time to listen and ask questions as they reflect on their life and the important job they did in valuing and caring for their family, or the way Mary can always be counted on to step in and help when extra hands are needed. Be sure to acknowledge the little things that mean so much to the residents, their families and coworkers that are the mark of an excellent caregiver.

An important aspect of creating team spirit is demonstrating that you are open to communication from everyone, including residents, families and staff. When you walk through the unit be sure you smile, are friendly, and acknowledge people you pass. You should always show that you are aware of and care about each person. This will demonstrate to them that you are aware of them as people, and are also aware of what's happening on the unit. By doing this you will also demonstrate that you are willing to listen and are responsive to their needs. 
There are many other ways a supervisor can foster team spirit. Some of these are:

- Give verbal and written communication to individuals and the group for jobs well done.

- Make sure team members know a bit about each other's personal life by setting aside 5 minutes at each staff meeting to have one person tell about something positive that's happened in their life in the past month.

- Find reasons to celebrate together, such as birthdays, birth of a baby or grandchild, moving into a new house, etc., and have small parties to celebrate these events. It's especially good to share your celebration with all the shifts on your unit by asking food services to provide a cake, and putting up a sign or banner in the break room saying "Today We Are Celebrating..............". By celebrating together you will be connecting the entire staff.

- Let them know that you are also part of the team by asking your staff what they need from you to make their job more satisfactory, and doing your best to provide it.

- Schedule stretch exercises that you do together before report. Have different staff members lead the exercises each day.

- Ensure that humor is part of the daily work environment. Put a humor section on the bulletin board and invite team members to post things they find funny (keeping good taste in mind, of course). Also, encourage them to respectfully find the humor in situations at work. It's important for you as the supervisor to learn to laugh at yourself, and model this for your staff. Let them know that since we all are human we make mistakes. It's much better to find the lesson and humor in mistakes than to become upset over them.

- Do problem solving and awareness exercises at staff meetings. For example: Have your staff members each write a list of 10 things that are important to them, and then have the person next to them cross off one thing. Then talk about what it feels like for them to lose this thing from their life, and relate it to what the residents may be feeling about all they have lost as they age.

\section{Give Recognition and Appreciation}

Whenever you can, 'catch people being good' and make sure they and others know about it. Give recognition and appreciation to everyone at every opportunity. For example: "Susan, I appreciate your organizational skills and the way you organized your team today to deliver quality care." "James, thank you for staying overtime yesterday. I really appreciate your positive, can-do attitude." When verbalizing appreciation try to make it as personal as possible. Rather than just saying something vague like "good job", be specific about the personal quality or skill your team member brought to the task. Recognizing excellent job performance and attitude, and showing appreciation for these things will go a long way towards making your staff members feel that they are a valued and respected part of the team.

\section{Give Credit and Take Responsibility}

Always give credit for success to your staff, and take responsibility when things don't go well. As the boss it's your job to make sure your staff is well trained, capable and competent. If for some reason they fail to perform their job in the expected manner, it's your responsibility to insure that they receive further direction and training so they will perform up to standards.

\section{Be Approachable}

Always present an attitude of approachability to your staff and customers. Indicate by your manner that you are available and happy to speak with people from all levels and positions. Also, always be prepared to listen to whatever they want to share with you, and validate what you've heard. If they have concerns, tell them you will look into it and get back to them by a certain time. Then be sure you do! It's important that every day you go out and walk about your business in order to connect with people. Be sure that as you walk through the business you smile and make eye contact with everyone you pass. Act in a friendly manner, call people by name, be approachable, and show interest in what's going on. Also, have an open door policy, where anyone at any level is welcome to come talk with you if they feel the need. When they do come talk with you, be aware of your body language. Come around to the front of your desk and sit facing them while you talk so that there is no physical barrier between you. Indicate in everything you do that you respect and care about them and what they are saying.

\section{Provide A Positive Physical Environment}

If at all possible insure that the physical environment on your workplace is clean, bright, attractive and cheerful. Make sure it has as much natural light as possible, and that each staff member has room for their own personal space. 


\section{Make Staff Evaluations a Positive Experience}

One of the important duties of a boss is to give staff evaluations. This should be a positive experience for your staff members, and is a great opportunity for you to praise them for their cooperative spirit and all their efforts in doing an excellent job. It's also a good time to thank them for participating by bringing their special characteristics and talents to the unit. Even if you need to discuss some areas in which the employee may need improvement, you can still make it a positive meeting by focusing on the good and all that they are doing right.

Insure that the staff evaluation is two-way. It's an opportunity for the employee to rate him/herself and also to rate you and your business. It's also the time to mutually create their career goals. Prior to the meeting, ask the employee to write out their evaluation of how they think they are doing in their job. Also ask them to write how they view you as a supervisor, and how they feel about working in your business. You will fill out the organization's standard evaluation form and write your thoughts on the employee's performance. Remember to keep it as positive as possible, and make suggestions in a constructive, encouraging manner.

Once you are in the meeting, ask the employee to share what they have written, and then discuss it with them. Then share your thoughts and what you have written. Some things to cover are:

- What skills would you like to develop in the next six months?

- What new knowledge would you like to gain in the next six months?

- What would you like to do differently with your peers?

- What can I do to assist you in the process of your development?

This is also an opportunity for you to revisit any difficult situations this staff member has experienced in the past six months and insure that they are feeling $\mathrm{OK}$ about it and are moving forward. You do this by asking:

- How are you feeling now about the conflict two months ago?

- What else needs to be done to resolve it?

- Is there anything I can do to help?

One of the most difficult aspects of a manager's job is counseling an employee who is not performing up to standards. Always put a positive spin on whatever you say, even if it's offering constructive suggestions. When dealing with negatives, separate all emotions from the issues, and deal only with the facts. Ask the worker what s/he can do differently next time. Ask how s/he would like to change his/her behavior in order to perform up to standards. Then create a written work plan to outline what the new behaviors will be and by when they will be implemented.

If there has been a problem it should not be a surprise to the employee when it's brought up at the evaluation. It's probably been discussed at the time of the incident, and several follow-up meetings will have been held regarding the progress or lack of progress with this issue. If appropriate, evaluation time is the opportunity for you to voice your appreciation for how the employee has changed his or her behavior to improve the quality of their work.

Your role and responsibility as the manager is to support the employee through this process. The outcome may be that the employee will choose to continue working in your business or may choose to leave.

At the end of the evaluation process your staff member needs to be able to leave the meeting feeling that he/she has some control and personal power over their work life. This is a basic human need, and it's your job to support them by focusing on their strengths rather than their weaknesses. This doesn't mean you don't address their areas for growth, it just means that you focus on your belief in their ability to perform according to the needs of your business.

The bottom line for all of this is to remember that as the manager it's your job to make your work environment one in which people can feel comfortable, have fun and can thrive. With a little thought and creativity you can make it happen.

\section{Make It Fun}

Everyone wants to be where people are having fun, so make your workplace feel happy and festive. Find reasons to celebrate together, such as birthdays, birth of a baby or grandchild, moving into a new house, etc., and having small parties to celebrate these events. If possible provide a cake, and put up a sign or banner in the break room saying "Today We Are Celebrating..............". Ask your employees what would be fun for them and then implement what is feasible.

\section{Conclusion:}

A positive work environment improves on employee attitude. This depends on other employees, the management and the available resources. Providing positive working environment by building trust, communicating positively and openly, Creating Team Spirit and by Giving Recognition and Appreciation then their productivity will improve. Job productivity increases a business performance and profits, which in turn ensures that employees receive their salary frequently. When the business performs well then the employees are happy. A good performance in the organization gives the employees a positive attitude that improves their 
individual performance. As long as the employees are happy and performing, job productivity will increase. Job satisfaction improves employee's relationships with customers. A good working relationship such as that one will increase on the sales of goods and services.

\section{References:}

[1]. Human Behavior and the Social Environment: Shifting Paradigms in Essential Knowledge for Social Work Practice (5th Edition) by Joe M. Schriver (Jan 20, 2010)

[2]. Fun Works: Creating Places Where People Love to Work by Leslie Yerkes and Jim Kouzes (Apr 28, 2007)

[3]. JEM Performance Consulting. The Power of a Positive Work Environment. www.jemperformance.com accessed 6 July 2011

\section{Websites:}

[4]. www.citehr.com

[5]. www.ijecbs.com/January2011/N4Jan2011.pdf

[6]. www.gret.umontreal.ca/images/article\%20002.pdf

[7]. www.allbusiness.com/management/4501634-1.html

[8]. www.jstor.org/stable/256046

[9]. www.ncbi.nlm.nih.gov 